\title{
Neurotoxicity among pesticide applicators exposed to organophosphates
}

\author{
Lynette Stokes, Alice Stark, Elizabeth Marshall, Amarjit Narang
}

\begin{abstract}
Objectives-An epidemiological study of 90 male pesticide applicators licensed in New York was conducted to investigate the effect of exposure to organophosphate pesticides on the peripheral nervous system.

Methods-A cohort of farmers and pesticide applicators from New York State were questioned off season (November 1988-February 1989) and again during the spraying season (April 1989-August 1989) about the presence of several acute signs and symptoms. Short term exposure was validated by measuring the concentration of dimethylthiophosphate (DMTP), a metabolite of guthion, in urine. Chronic signs of subtle peripheral nerve damage were determined by vibration threshold sensitivity of the farmers and applicators tested during November 1988-February 1989 and compared with controls drawn from the general population who were tested during the same time period the next year (November 1989-February 1990). Vibration threshold sensitivity was determined for both the hands and feet. Long term exposure to pesticides was determined by questionnaire.
\end{abstract}

Results-Paired $t$ tests show that mean vibration threshold scores were significantly higher for the dominant $(P<0.00)$ and non-dominant $(P<0.04)$ hands among pesticide applicators when compared with scores for population based controls individually matched on age, sex, and county of residence.

Conclusions-A significant increase in mean vibration threshold sensitivity for the dominant and non-dominant hand suggests previous organophosphate exposure among pesticide applicators was associated with a loss of peripheral nerve function.

(Occup Environ Med 1995;52:648-653)

Keywords: vibration sensitivity; method of limits guthion

Among agricultural pesticides used both in the United States and elsewhere organophosphates are replacing many products because they are effective and less persistent than compounds such as DDT and lead arsenate. With the increase in production and use of organophosphates, the number of people exposed to these compounds has increased.

Symptoms of acute poisoning are well known. These develop within 12 hours of contact. Headache, dizziness, weakness, lack of coordination, muscle twitching, tremor, nausea, abdominal cramps, diarrhoea, and sweating are common early signs and symptoms.

The effects of repeated low dose exposure to organophosphates have not been as well established. There have been some reports of delayed onset of neurological problems, including numbness, pain, and weakness in the arms and legs. ${ }^{2}$ In some people recovery has been complete, whereas others have been left with continuing problems. ${ }^{3-7}$ Specifically, what is not known is whether long term, low concentration exposure can produce delayed subclinical damage to the peripheral nervous system.

This study examined two related but separate questions. The first question was whether current, short term exposure to guthion was producing acute health effects. The second question was whether subtle damage to peripheral nerves resulted from long term, low concentration exposure to organophosphates. To answer these questions, a cohort of pesticide applicators from New York State were questioned off season (November 1988-February 1989) and again during the spraying season (April 1989-August 1989) about the presence of several acute signs and symptoms. Short term exposure was validated by measuring concentrations of dimethylthiophosphate (DMTP), a metabolite of guthion, in urine.$^{89}$ Chronic signs of peripheral nerve damage were determined by vibration sensitivity thresholds of farmers and applicators tested during November 1988-February 1989 and compared with controls drawn from the general population and tested during the same time period the next year (November 1989-February 1990). Long term exposure to pesticides was determined by questionnaire.

\section{Methods}

The source population for this study was the roster of 554 male pesticide applicators licensed to apply pesticides in New York by the New York State Department of Environmental Conservation. Farms from 11 south eastern counties of New York were 
targeted for the study. Applicators were eligible for the study if they had a current pesticide applicator licence, were scheduled to spray in the next growing season, and were located in the 11 south eastern counties.

Pesticide applicators were recruited in south eastern New York by post, announcements in the Cornell University extension newsletter, visits to area farms, and during horticultural and agricultural meetings.

Population based controls individually matched to applicators on age ( \pm 1 year), sex, and county of residence were identified through the Department of Motor Vehicle (DMV) records and were recruited by post.

Among the 554 licensed pesticide applicators in south eastern New York, a total of 90 participated. Also, among the 450 potential population based controls 68 agreed to participate. For each of the 90 pesticide applicators, five potential matched controls were identified from the DMV records. Letters from the New York State Department of Public Health were sent to potential control subjects requesting their participation. Telephone numbers were obtained from directory assistance and each name was called until one of the five potential control subjects agreed to participate. Potential control subjects without working telephone numbers were eliminated from the study. Once the pesticide applicators and controls agreed to participate in the study, all subjects signed informed consent forms.

Chronic signs of peripheral nerve damage were determined by testing vibration sensitivity thresholds of farmers and applicators during November 1988-February 1989 and compared with controls drawn from the general population who were tested during the same time period the next year (November 1989-February 1990). Long term exposure to pesticides was determined by questionnaire. Also, information was collected on sociodemographic characteristics, medical and lifestyle factors, work history, and potential confounders such as diabetes, alcoholism, carpal tunnel syndrome, and exposure to heavy metals.

Also, pesticide applicators were questioned both off season (November 1988-February 1989) and again during the spraying season (April 1989-August 1989) about the presence of several acute signs and symptoms. Short term exposure was validated by measuring concentrations of dimethylthiophosphate (DMTP), a metabolite of guthion, in urine ${ }^{89}$ during the spraying season (April 1989August 1989).

\section{CHRONIC EFFECTS}

Vibration threshold sensitivity was used as an indicator of chronic neurotoxicity. The reliability of this measurement has been described elsewhere by Gerr and Letz. ${ }^{10}$ Vibration thresholds were determined with a Vibratron II for both upper and lower extremities of the distal volar pad of the right and left index fingers and great toes. The vibration sensitivity frequency was $120 \mathrm{~Hz}$. The method of limits procedure began with the delivery of a stimulus greater than the threshold that the subject could easily detect. ${ }^{10}$ The intensity of the stimulus was gradually reduced at a constant rate. The complete testing sequence consisted of five trials (three descending and two ascending).

\section{ACUTE EFFECTS}

Acute symptoms of exposure to organophosphate pesticides were identified from answers to questions about 22 signs and symptoms such as blurred vision, headache, diarrhoea, dizziness, and unexplained sweating. For each symptom, it was asked whether the subject had ever experienced that symptom, when the symptom was first noticed (year), and whether he was currently bothered or affected by that symptom. These questions were asked both on season and off season. The total number of symptoms reported among pesticide applicators both on and off season were compared. The number of symptoms reported by pesticide applicators on season was also correlated with the concentration of urinary metabolite collected during the same on season time period.

\section{STATISTICAL METHODS}

Statistical tests performed compared 68 pesticide applicators with 68 individually matched population based controls for vibration threshold sensitivity for all extremities (right and left index finger and right and left great toe). The mean (SD) vibration threshold sensitivity was determined for all extremities. Pairwise (one tailed) $t$ tests, with $a=0.05$, were used to test whether there was a significant difference in vibration threshold. ${ }^{112}$ None of the vibration scores were normally distributed. Therefore, the scores were transformed to $\log$ microns. ${ }^{10}$

The second separate hypothesis tested determined whether there was a significant difference in the number of reported symptoms among pesticide applicators off season and on season. McNemar's tests were performed on the individual on and off season responses of 81 pesticide applicator pairs. ${ }^{11}$ Twenty two acute symptoms related to organophosphates were tested. The discordant pairs provide the point estimate and $95 \%$ confidence interval ( $95 \% \mathrm{CI})$.

\section{Results}

Ninety male pesticide applicators licensed in New York State who spray apple orchards and 68 population based controls agreed to participate in the study. Table 1 shows the age distribution and other demographic characteristics of the 68 applicators and 68 individually matched population based controls. The sociodemographic characteristics and current alcohol consumption were similar among applicators and controls (table 2). Controls reported significantly more neurological disorders and alcoholism than applicators (table 2). Applicators reported more kidney disease than controls but these differences were not significant. 
Table 1 Age distribution and sociodemographic characteristics of applicators and matched population based controls

\begin{tabular}{lcc}
\hline & $\begin{array}{l}\text { Pesticide } \\
\text { applicators } \\
n=68(\%)\end{array}$ & $\begin{array}{c}\text { Population } \\
\text { controls } \\
n=68(\%)\end{array}$ \\
\hline $20-29$ & $10(14 \cdot 7)$ & $9(13 \cdot 2)$ \\
$30-39$ & $17(25 \cdot 0)$ & $18(26 \cdot 5)$ \\
$40-49$ & $17(25 \cdot 0)$ & $16(23 \cdot 5)$ \\
$50-59$ & $15(22 \cdot 0)$ & $15(22 \cdot 1)$ \\
$60-69$ & $7(10 \cdot 2)$ & $8(11 \cdot 8)$ \\
$70-79$ & $2(2 \cdot 9)$ & $2(2 \cdot 9)$ \\
Total & $68(100 \cdot 0)$ & $68(100 \cdot 0)$ \\
Household income: & $3(4 \cdot 4)$ & \\
$<\$ 10$ 000 & $19(27 \cdot 9)$ & $2(2 \cdot 9)$ \\
$10000-20000$ & $30(44 \cdot 1)$ & $3(4 \cdot 4)$ \\
$20000-40000$ & $16(23 \cdot 5)$ & $25(36 \cdot 8)$ \\
$>40000$ & & $38(55 \cdot 9)$ \\
Education: & $9(13 \cdot 2)$ & $7(10 \cdot 3)$ \\
$<12$ years & $38(55 \cdot 8)$ & $35(51 \cdot 5)$ \\
12+ some college & $21(30 \cdot 8)$ & $26(38 \cdot 2)$ \\
$\geqslant$ college degree & & \\
Marital state: & $62(91 \cdot 1)$ & $54(79 \cdot 4)$ \\
Ever married & $6(8 \cdot 8)$ & $14(20 \cdot 6)$ \\
Never married & & \\
Race: & $65(95 \cdot 5)$ & $67(98 \cdot 5)$ \\
White & $2(2 \cdot 9)$ & $1(1 \cdot 5)$ \\
Black & $1(1 \cdot 4)$ & $0(0 \cdot 0)$ \\
Other & & \\
\hline
\end{tabular}

Table 2 Prevalence of self-reported chronic conditions, smoking and alcohol consumption among applicators and matched controls

\begin{tabular}{|c|c|c|}
\hline & $\begin{array}{l}\text { Pesticide } \\
\text { applicators } \\
n=68(\%)\end{array}$ & $\begin{array}{l}\text { Population } \\
\text { controls } \\
n=68(\%)\end{array}$ \\
\hline $\begin{array}{l}\text { Neurological disorder } \\
\text { Carpal tunnel syndrome } \\
\text { Neck or back problems } \\
\text { Injury to arms or legs } \\
\text { Alcoholism } \\
\text { Diabetes } \\
\text { Kidney problems } \\
\text { Numbness or tingling or }\end{array}$ & $\begin{array}{c}2(2 \cdot 9) \\
0(0 \cdot 0) \\
18(26 \cdot 4) \\
6(8 \cdot 8) \\
0(0 \cdot 0) \\
0(0 \cdot 0) \\
6(8 \cdot 8)\end{array}$ & $\begin{array}{c}11(16 \cdot 2) \\
2(2 \cdot 9) \\
19(27 \cdot 9) \\
13(19 \cdot 1) \\
6(8 \cdot 8) \\
3(4 \cdot 4) \\
1(1 \cdot 5)\end{array}$ \\
\hline $\begin{array}{l}\text { Weakness in arms or legs } \\
\text { Ever smoked cigarettes } \\
\text { Ever smoked marijuana } \\
\text { Alcohol consumption }\end{array}$ & $\begin{array}{r}8(11 \cdot 7) \\
29(42 \cdot 6) \\
10(14 \cdot 7)\end{array}$ & $\begin{array}{l}17(25 \cdot 0) \\
41(60 \cdot 3) \\
17(25 \cdot 0)\end{array}$ \\
\hline $\begin{array}{l}\text { Current drinker } \\
\text { Current alcohol } \\
\text { consumption }\end{array}$ & $61(89 \cdot 7)$ & $60(88 \cdot 2)$ \\
\hline $\begin{array}{l}\text { <1 Drink/day } \\
1-2 \text { Drinks/day } \\
\geqslant 3 \text { Drinks/day }\end{array}$ & $\begin{array}{c}41(67 \cdot 2) \\
16(26 \cdot 2) \\
3(4 \cdot 9)\end{array}$ & $\begin{array}{r}37(61 \cdot 7) \\
15(25 \cdot 0) \\
8(13 \cdot 3)\end{array}$ \\
\hline
\end{tabular}

ॠMissing one among current drinkers

Table 3 Number of years applicators have sprayed top five organophosphates (OP) on apples

\begin{tabular}{ccc}
\hline & $\begin{array}{l}\text { Pesticide } \\
\text { applicators } \\
n=90(\%)\end{array}$ & $\begin{array}{c}\text { Pesticide } \\
\text { applicators } \\
n=81(\%)\end{array}$ \\
\hline Guthion: & & \\
$0-9$ & $27(30 \cdot 0)$ & $20(29 \cdot 4)$ \\
$10-19$ & $30(33 \cdot 3)$ & $22(32 \cdot 3)$ \\
$20-29$ & $30(33 \cdot 3)$ & $21(30 \cdot 9)$ \\
$>30$ & $3(3 \cdot 3)$ & $5(7 \cdot 3)$ \\
Mean & 14 & 14 \\
Phosphamidon: & $63(70 \cdot 0)$ & $47(69 \cdot 1)$ \\
$0-9$ & $16(17 \cdot 8)$ & $12(17 \cdot 6)$ \\
$10-19$ & $9(10 \cdot 0)$ & $7(10 \cdot 3)$ \\
$20-29$ & $2(2 \cdot 2)$ & $2(2 \cdot 9)$ \\
$>30$ & 7 & 7 \\
Mean & $83(92 \cdot 2)$ & $61(89 \cdot 7)$ \\
Chlorpyrifos: & $7(7 \cdot 8)$ & $7(10 \cdot 3)$ \\
$0-9$ & 4 & 4 \\
$10-20$ & $74(82 \cdot 2)$ & $52(76 \cdot 5)$ \\
Mean & $14(15 \cdot 6)$ & $11(16 \cdot 2)$ \\
Phosmet: & $2(2 \cdot 2)$ & $5(7 \cdot 3)$ \\
$0-9$ & 4 & 5 \\
$10-19$ & $88(97 \cdot 8)$ & $67(98 \cdot 5)$ \\
$20-30$ & $2(2 \cdot 2)$ & $1(1 \cdot 5)$ \\
Mean & 1 & 1 \\
Diazinon: & & \\
$0-9$ & & \\
$10-20$ & &
\end{tabular}

USE OF ORGANOPHOSPHATE PESTICIDES BY APPLICATORS

Pesticides had been sprayed for a mean of 20 (range 1-52) years by applicators. Twenty seven $(30 \%)$ of the applicators had sprayed pesticides for 30 years or more. Thirteen (14\%) had sprayed for between 20 and 30 years, and $27(30 \%)$ had sprayed for between 10 and 19 years. Also, 22 (24\%) had sprayed for between one and nine years. Of the 11 most frequently used organophosphates, guthion was predominantly used by $78(86 \%)$ applicators during the previous two growing seasons.

Table 3 shows that the mean number of years the top five organophosphates had been used by 90 pesticide applicators and the subset of 68 applicators matched with population based controls. Guthion had been sprayed for a mean of 14 (range 1-39) years by the applicators. Guthion was also the predominant organophosphate sprayed during the growing season. On average, the organophosphate was sprayed five times a season or more by 55 of the $90(61 \%)$ applicators during a normal growing season.

Protective clothing and devices were used by some pesticide applicators, $93 \%$ of the applicators used some type of head covering more than half the time; at least $60 \%$ of the applicators used overalls and rubber gloves more than half the time; about $35 \%$ used respirators or rubber boots, or both, and about $35 \%$ have tractor cabs. Tractor cabs are enclosed quarters on the tops of tractors; some are air conditioned enclosures and some are not.

Table 4 shows the total number of tanks loaded, acres and hours sprayed, and the average amount of DMTP recovered in parts per million (ppm) from urine samples. As expected, DMTP recovered from on season urine samples increased with increasing number of hours sprayed, acres sprayed, and tanks loaded.

\section{CHRONIC EFFECTS}

The mean difference for the paired dominant and non-dominant hands was significant with the applicators having higher vibration threshold sensitivity scores than population based controls (table 5). The mean difference for paired dominant and non-dominant feet was not significantly different between applicators and controls. Pesticide applicators had higher vibration sensitivity scores than controls indicating poorer performance.

The paired $t$ tests were repeated after eliminating applicators and controls who reported diabetes and carpal tunnel syndrome and results were essentially the same.

ACUTE EFFECTS

Table 6 presents the symptoms related to organophosphates reported by applicators off season and on season and odds ratios (ORs) and $95 \%$ CIs for matched pairs. Of all symptoms related to organophosphates, only frequent headaches $(22.2 \% v 8.8 \%)$ were reported significantly more on season than off 
Table 4 Number of tanks loaded, acres sprayed, hours sprayed, and DMTP recovered from urine samples

\begin{tabular}{|c|c|c|}
\hline & $\begin{array}{l}\text { Pesticide } \\
\text { applicators } \\
(n=53) \\
n(\%)\end{array}$ & $\begin{array}{l}\text { DMTP } \\
\text { recovered } \\
(n=53) \\
\text { mean (range) }\end{array}$ \\
\hline $\begin{array}{l}\text { Total tanks loaded (1-4 days): } \\
0 \cdot 5-5 \\
6-12 \\
13-53\end{array}$ & $\begin{array}{l}16(30 \cdot 1) \\
21(39 \cdot 6) \\
16(30 \cdot 1)\end{array}$ & $\begin{array}{l}40 \cdot 5(3 \cdot 7-143 \cdot 0) \\
75 \cdot 4(2 \cdot 0-396 \cdot 1) \\
96 \cdot 8(6 \cdot 3-298 \cdot 3)\end{array}$ \\
\hline $\begin{array}{l}\text { Total acres sprayed ( } 1-4 \text { days): } \\
0.5-20 \\
21-85 \\
86-265 \\
\text { Total hours sprayed ( } 1-4 \text { days): }\end{array}$ & $\begin{array}{l}17(32 \cdot 0) \\
22(41 \cdot 5) \\
14(26 \cdot 4)\end{array}$ & $\begin{array}{r}56 \cdot 2(2 \cdot 0-396 \cdot 1) \\
62 \cdot 2(3 \cdot 7-274 \cdot 3) \\
103 \cdot 9(6 \cdot 3-298 \cdot 3)\end{array}$ \\
\hline $\begin{array}{l}0.5-8 \\
9-18 \\
19-61\end{array}$ & $\begin{array}{l}21(39 \cdot 6) \\
19(35 \cdot 8) \\
13(24 \cdot 5)\end{array}$ & $\begin{array}{r}39 \cdot 0(2 \cdot 0-143 \cdot 0) \\
72 \cdot 5(3 \cdot 7-274 \cdot 3) \\
121 \cdot 8(7 \cdot 5-396 \cdot 1)\end{array}$ \\
\hline
\end{tabular}

Table 5 Mean (SD) vibration threshold scores and paired t tests in applicators and matched controls

\begin{tabular}{|c|c|c|c|c|}
\hline \multirow[b]{2}{*}{ Variable } & \multirow{2}{*}{$\begin{array}{l}\text { Pesticide } \\
\text { applicators } \\
(n=68) \\
\log \text { microns }\end{array}$} & \multirow{2}{*}{$\begin{array}{l}\begin{array}{l}\text { Population } \\
\text { controls } \\
(n=68)\end{array} \\
\log \text { microns }\end{array}$} & \multicolumn{2}{|c|}{$\begin{array}{l}\text { Applicator/control } \\
\text { pairs } \\
(n=68)\end{array}$} \\
\hline & & & $t$ value & Pvalue \\
\hline $\begin{array}{l}\text { Dominant hand } \\
\text { Non-dominant hand } \\
\text { Dominant foot } \\
\text { Non-dominant foot }\end{array}$ & $\begin{array}{l}0.534(0.71) \\
0.340(0.76) \\
2 \cdot 25(1 \cdot 19) \\
2 \cdot 13(1 \cdot 14)\end{array}$ & $\begin{array}{l}0.134(0.79) \\
0.080(0.80) \\
1.96(1.20) \\
1.97(1.34)\end{array}$ & $\begin{array}{l}3 \cdot 27 \\
2 \cdot 06 \\
1 \cdot 77 \\
0.99\end{array}$ & $\begin{array}{l}0.00 \\
0.04 \\
0.08 \\
0.32\end{array}$ \\
\hline
\end{tabular}

Log microns $=\log \left(0.356 \times{\left.\text { vibration } \text { unit }^{2.09}\right)}^{2}\right.$

Table 6 Organophosphate symptoms reported off and on season in 81 pesticide applicator pairs

\begin{tabular}{|c|c|c|c|c|c|}
\hline Symptom & $\begin{array}{l}\text { Off season } \\
(n=81) \\
n(\%)\end{array}$ & $\begin{array}{l}\text { On season } \\
(n=81) \\
n(\%)\end{array}$ & $\begin{array}{l}\text { Discordant } \\
\text { pairs }\end{array}$ & OR & $(95 \% C I)$ \\
\hline Blurred vision & $7(8 \cdot 6)$ & $5(6 \cdot 1)$ & $2 / 4$ & 0.5 & $(0.03-4.3)$ \\
\hline Slurred speech & $5(6 \cdot 1)$ & $2(2 \cdot 5)$ & $2 / 5$ & 0.4 & $(0.02-2.9)$ \\
\hline Difficulty swallowing & $4(4.9)$ & $4(4.9)$ & $3 / 3$ & $1 \cdot 0$ & $(0 \cdot 10-9 \cdot 3)$ \\
\hline Sick stomach & $4(4.9)$ & $7(8 \cdot 6)$ & $5 / 2$ & $2 \cdot 5$ & $(0.33-37.9)$ \\
\hline Muscle weakness & $4(4 \cdot 9)$ & $3(3 \cdot 7)$ & $3 / 4$ & $0 \cdot 7$ & $(0 \cdot 08-5 \cdot 3)$ \\
\hline Frequent headache & $8(9 \cdot 8)$ & $18(22 \cdot 2)$ & $12 / 2$ & $6 \cdot 0$ & $(1 \cdot 01-77 \cdot 6)$ \\
\hline Balance problems & $7(8 \cdot 6)$ & $3(3 \cdot 7)$ & $3 / 7$ & 0.4 & $(0 \cdot 06-2 \cdot 1)$ \\
\hline Dizziness & $14(17 \cdot 2)$ & $10(12 \cdot 3)$ & $7 / 11$ & 0.6 & $(0 \cdot 19-1 \cdot 9)$ \\
\hline Sleep problems & $13(16.0)$ & $16(19 \cdot 7)$ & $10 / 7$ & $1 \cdot 4$ & $(0 \cdot 44-4 \cdot 7)$ \\
\hline Frequently tired & $13(16 \cdot 0)$ & $10(12 \cdot 3)$ & $7 / 11$ & 0.6 & $(0 \cdot 19-1 \cdot 9)$ \\
\hline Excessive sweating & $4(4.9)$ & $5(6 \cdot 1)$ & $3 / 2$ & 1.5 & $(0 \cdot 13-26 \cdot 6)$ \\
\hline Coordination problems & $1(1 \cdot 2)$ & $3(3 \cdot 7)$ & $3 / 1$ & $3 \cdot 0$ & - \\
\hline Numbness or tingling & $15(18 \cdot 5)$ & $12(14 \cdot 8)$ & $7 / 10$ & $0 \cdot 7$ & $(0 \cdot 20-2 \cdot 2)$ \\
\hline Weight loss or gain & $1(1 \cdot 2)$ & $9(11 \cdot 1)$ & $9 / 1$ & $9 \cdot 0$ & - \\
\hline Muscle pain & $5(6 \cdot 1)$ & $9(11 \cdot 1)$ & $7 / 3$ & $2 \cdot 3$ & $(0 \cdot 45-16 \cdot 6)$ \\
\hline Diarrhoea & $3(3 \cdot 7)$ & $8(9 \cdot 9)$ & $5 / 0$ & - & - \\
\hline Tension or nervousness & $10(12 \cdot 3)$ & $18(22 \cdot 2)$ & $12 / 4$ & $3 \cdot 0$ & $(0 \cdot 79-14 \cdot 1)$ \\
\hline Depression & $9(11 \cdot 1)$ & $11(13 \cdot 6)$ & $7 / 5$ & $1 \cdot 4$ & $(0.34-6 \cdot 2)$ \\
\hline Irritability & $18(22 \cdot 2)$ & $18(22 \cdot 2)$ & $8 / 8$ & $1 \cdot 0$ & $(0 \cdot 30-3 \cdot 3)$ \\
\hline Nightmares & $3(3 \cdot 7)$ & $8(9 \cdot 9)$ & $6 / 1$ & $6 \cdot 0$ & - \\
\hline Memory problems & $17(20.9)$ & $15(18 \cdot 5)$ & $8 / 10$ & 0.8 & $(0 \cdot 25-2 \cdot 4)$ \\
\hline Sense of smell & $11(13 \cdot 5)$ & $11(13 \cdot 6)$ & $8 / 8$ & $1 \cdot 0$ & $(0 \cdot 30-3 \cdot 3)$ \\
\hline
\end{tabular}

season (OR 6, 95\% CI 1·01-77·6). Also, increased point estimates were found for many of the symptoms related to organophosphates. Small numbers of discordant pairs were found for each of the symptoms.

\section{Discussion}

Pesticide application was associated with a significant increase in mean (SD) vibration threshold among applicators compared with population based controls for the dominant $(0.534(0.71) v 0.134(0.79))$ and non-dominant hand $(0.340(0.76) v 0.080(0.80))$. The effects were not significant for feet, but mean vibration sensitivity scores were higher for pesticide applicators than for controls indicating poorer performance. Subjects with a history of diabetes and carpal tunnel syndrome were removed in the analysis, and results remained the same. It was important to remove cases of diabetes and carpal tunnel syndrome from the sample because both chronic disorders adversely affect vibration sensitivity threshold. ${ }^{13-15}$

The difference among applicators and controls may have resulted from long term exposure to pesticides by farmers. This is a biologically plausible explanation. The peripheral nerves are accessible to toxins through the bloodstream; the blood nerve barrier does not protect the peripheral nerves. ${ }^{14}$

Two studies in the scientific literature support the findings of our study. Svendsgaard et al investigated 229 male organophosphate production workers in Egypt and compared their vibration threshold scores with those of workers in nearby textile $(n=180)$ and fertiliser $(n=167)$ plants. $^{4}$ After controlling for covariates, vibration threshold scores measured in the non-dominant hand were significantly higher among pesticide formulation workers than workers in the other two plants. The vibration threshold scores of workers exposed to pesticides increased dramatically with increasing age but did not similarly increase among the comparison workers. The authors suggest that exposure to organophosphate pesticides accelerates the aging process of the nervous system.

In another study conducted by McConnell et $a l^{5}$ vibration threshold in the hands and feet was evaluated in 36 subjects poisoned by organophosphates in Leon, Nicaragua. Results showed that the workers poisoned had significantly higher vibration threshold scores for all extremities than controls. Furthermore, vibration threshold significantly increased with increasing organophosphate exposure. In our study, mean vibration threshold scores for the upper extremities were comparable with the "poisoned" exposure category but were not as high as the "severely poisoned" category.

There are other explanations for the association between long term pesticide exposure and increased mean vibration threshold sensitivity, but these seem less plausible. Inadequate control of confounders may explain the significant differences between applicators and controls. Alcoholics among pesticide applicators may not have reported their alcoholism. Underreporting of alcoholism, however, may underestimate the effect of vibration sensitivity in pesticide applicators. It seems unlikely that pesticide applicators would underreport alcoholism at a higher rate than population based controls. The small number of applicators and controls who reported alcoholism may not provide sufficient power to determine the relation between the effect of alcohol and pesticides on vibration threshold sensitivity.

The significant difference between applicators and controls in the upper extremities could be the result of differences in height. Height was not measured in our study. Recent studies by Gerr et $a l^{13}$ have shown that height significantly predicts vibration threshold in 
the hands and feet, and these effects were substantially larger in the lower extremities, which had much higher variability than the upper extremities. In our study, vibration threshold scores in the feet were not statistically different. The lack of significant difference could result from a lack of sample size necessary to detect small differences in a highly variable measurement. In our study, sample size calculations for vibration sensitivity showed that 68 controls were required to detect (with $80 \%$ power) a $20 \%$ significant change $(\delta=20 \%)$ in vibration sensitivity between the pesticide applicators and population based controls for a one sided significance test. If the true difference between applicators and controls in the lower extremities was less than $20 \%$, then the current study may not have been able to detect it.

Increased use of machinery that vibrates may explain the difference found in the upper extremities between applicators and controls. Pesticide applicators use several vibrating machines such as tractors, loading cars, and lifting apparatus for pruning trees. Studies by Svendsgaard et al suggested that vibration threshold scores of workers who used vibrating tools in an organophosphate pesticide formulation plant were not significantly different from those of controls. ${ }^{4}$ The total number of organophosphate pesticide formulation workers studied was 229 , and about half of the sample had worked at the plant for more than 12 years. Consequently, it does not seem likely that increased exposure to vibrating machinery among applicators compared with controls could explain the significant difference found in the upper extremities.

Finally, the difference between applicators and controls could have resulted from pesticide exposure to many different pesticides over several years of application. Other classes of pesticides, such as carbamates, have been used by the sample of pesticide applicators. Many of these compounds are neurotoxins and may have produced a significant reduction in nerve function.

The evaluation of short term exposure and acute effects showed that growers were exposed to guthion but did not show acute symptoms of organophosphate poisoning. Applicators reported headaches more frequently on than off season. Because several symptoms were investigated, it is highly possible that significant associations and increased point estimates have occurred by chance. In a more recent study by Ciesielski et al, ${ }^{16}$ farmworkers (acetylcholinesterase concentrations $<25.28 \mathrm{U} / \mathrm{g}$ ) were three times more likely than non-farmworkers to report symptoms of diarrhoea after exposure to organophosphates. In our study, short term exposure was verified by recovery of the urinary metabolite DMTP. Among the 53 urine samples from applicators who had been exposed to guthion during the 1989 growing season, DMTP did not increase with increasing number of symptoms reported. The results suggest that the DMTP urinary metabolite concentrations we recovered do not have a dose-dependent relation with acute symptoms of organophosphate poisoning. Concentrations of exposure may not have been high enough to produce acute effects in pesticide applicators. The results of acute effects should be interpreted with caution because of potential reporting bias among pesticide applicators and the relatively low concentrations of exposure. Studies investigating the concentration of DMTP recovered in the urine that correlate with acute organophosphate symptoms need to be conducted.

There are several limitations in our study. We evaluated a small sample of pesticide applicators who sprayed organophosphates on apples during a particular growing season and time period. Our results from the small proportion of all licensed applicators may not be representative of the population of all licensed pesticide applicators in south eastern New York. Possible bias could have occurred if applicators who did not participate were more likely to have had neurological impairment, but the opposite scenario is also possible. Height was not included in our study and has been shown to primarily effect vibration sensitivity measurements in the lower extremities. ${ }^{13}$ This may represent the lack of a significant association in vibration sensitivity from our study in the lower extremities. History of acute pesticide poisoning was not included in the study but has been shown to effect vibration sensitivity. ${ }^{17}$ Licensed applicators who have been trained in the appropriate methods of mixing and spraying pesticides most likely have not been poisoned. Our study cannot determine whether past poisoning has effected vibration sensitivity.

The current study measured acute symptoms and chronic effects from loss of peripheral nerve function in licensed pesticide applicators. Loss of peripheral nerve function may not represent permanent nerve damage. Vibration threshold scores estimate the somatosensory function of the peripheral nervous system; this function can be affected by many factors, both intrinsic and extrinsic. It should be noted that pesticide applicators are also exposed to other classes of insecticides, such as carbamates and pyrethroids. Many fungicides are also used by apple growers during the early growing season. These conditions of exposure may be unique and not represented elsewhere in other occupational groups. Furthermore, the concentration of organophosphate exposure in the past is not known. Consequently, it is difficult to determine whether high enough levels of exposure have occurred over time to contribute to the apparent loss of peripheral nerve function. The validity of the study results are supported by the biological plausibility and significance of the effects. More studies are needed of pesticide applicators to further evaluate the relation between nervous system function and organophosphate exposure.

We thank Drs Bailus Walker Jr, David Martin, and Jim Melius for their helpful advice throughout the project. This study was conducted in and supported by the Bureau of Environmental Department, Albany, New York. 
1 Ecobichon DJ, Joy RM. Pesticides and Neurological Disease. Boca Raton: CRC Press, 1982.

2 Abou-Donia MB. Organophosphorus ester-induced delayed neurotoxicity. Annu Rev Pharmacol Toxicol 1981;21: 511-48.

3 Bove FJ, Letz R, Baker EL. Sensory thresholds among construction trade painters: a cross sectional study using new methods for measuring temperature and vibration sensitivity. F Occup Med 1989;31:320-5.

4 Svendsgaard D, Soliman S, Otto D, et al. Assessment of neurotoxicity in workers occupationally exposed to organophosneurotoxicty in workers occupationally exposed to organophos-
phorus pesticides. Research Triangle Park, NC: US phorus pesticides. Research Triangle Park, NC: US ERvironment Pri178.)

5 McConnell R, Keifer M, Rosenstock L. Elevated tactile vibration threshold among workers previously poisoned with methamidofos and other organophosphate pesticides. Am $\mathcal{F}$ Ind Med 1994;25:325-34

6 Kraus JF, Richards DM, Borhani N, et al. Physiological response to organophosphate residues in field workers. Arch Environ Contam Toxicol 1977;5:471-85.

7 Richards DM, Kraus JF, Borhani N, et al. A controlled field trial of physiological responses to organophosphate residues in farm workers. F Environ Pathol Toxicol residues in farm

8 Franklin CA, Fenske RA, Greenhalgh $R$ et al. Correlation of urinary pesticide metabolite excretion with estimated dermal contact in the course of occupational exposure to guthion. $\mathcal{F}$ Toxicol Environ Health 1981;7:715-31.
9 Vasilic Z, Drevenkar V, Frobe Z, et al. The metabolites of organophosphorus pesticides in urine as an indicator of occupational exposure. Toxicology and Environmental Chemistry 1987;14:111-27.

10 Gerr FE, Letz R. Reliability of a widely used test of peripheral cutaneous vibration sensitivity and a comparison of two testing protocols. Br $\mathcal{f}$ Ind Med 1988;45:635-9.

11 Snedecor GW, Cochran WG. Statistical methods. Iowa: Iowa State University Press, 1967.

12 Kleinbaum DG, Kupper LL. Applied regression analysis and other multivariable methods. Massachusetts: Duxbury other multivar

13 Gerr FE, Hershman D, Letz $R$ Vibrotactile threshold measurement for detecting neurotoxicity: reliability and detersurement for detecting neurotoxicity: reliability and determination of age and height standardized
values. Arch Environ Health 1990;45:148-54.

14 Arezzo JC, Schaumburg HH, Spencer PS. Structure and function of the somatosensory system; a neurotoxicologic perspective. In: Toxicology of the eye, ear, and other special senses. New York: Raven Press, 1985.

15 Schaumburg HH, Spencer PS, Thomas PK. Disorders of peripheral nerves. Philadelphia: FA Davis Press, 1983.

16 Ciesielski S, Loomis DP, Mims SR, Auer A. Pesticide exposures, cholinesterase depression, and symptoms among North Carolina migrant farmworkers. Am $\Im$ Public Health 1994;84:446-51.

17 Steenland K, Jenkins B, Ames RG. Chronic neurological sequelae to organophosphate pesticide poisoning. Am $\mathcal{f}$ Public Health 1994;84:731-6.

\section{Instructions to authors}

Three copies of all submissions should be sent to: The Editor, Occupational and Environmental Medicine, BMJ Publishing Group, BMA House, Tavistock Square, London WC1H 9JR, UK. All authors should sign the covering letter as evidence of consent to publication. Papers reporting results of studies on human subjects must be accompanied by a statement that the subjects gave written, informed consent and by evidence of approval from the appropriate ethics committee. These papers should conform to the principles outlined in the Declaration of Helsinki ( $B M F$ 1964;ii:177).
If requested, authors shall produce the data on which the manuscript is based, for examination by the Editor.

Authors are asked to submit with their manuscript the names and addresses of three people who they consider would be suitable independent reviewers. They will not necessarily be approached to review the paper.

Papers should include a structured abstract of not more than 300 words, under headings of Objectives, Methods, Results, and Conclusions. Please include up to three keywords or key terms to assist with indexing. 